\title{
Poblaciones sin fronteras $y$ valorización del patrimonio cultural intangible: el caso de los gitanos
}

DOI: 10.22403/UQROOMX/TYP08/09

\author{
Anne-Marie Mamontoff \\ Universidad de Perpignan-Via Domitia \\ Institut Catalan de Recherches en Sciences Sociales
}

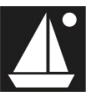

\section{Resumen}

A lo largo de su historia, Las comunidades gitanas han desarrollado un rico patrimonio cultural inmaterial cuya valorización puede significar un atractivo turístico en todas y cada una de sus expresiones artísticas. Además su reconocimiento por parte de la UNESCO le aportaría valor y ayudaría a que las comunidades gitanas mejoraran social y económicamente, en muchos casos saliendo de la marginalidad en la que se encuentran. En este trabajo exploratorio se han identificado las distintas formas de patrimonio cultural intangible gitano, la percepción de la población no gitana respecto a las posibilidades de integración de los gitanos y la visión de los poderes públicos. Los resultados obtenidos se enmarcan en las categorías previstas por la unesco,y se reconocen los tópicos y los estigmas sociales hacia los gitanos, contribuyendo los poderes públicos, sin quererlo, a la estigmatización social y a la marginalidad.

\footnotetext{
Palabras | Gitano, unesco, patrimonio cultural inmaterial, flamenco, CLAVE marginación social
} 


\section{Introducción}

A pesar de que las poblaciones gitanas han sido estigmatizadas y marginadas por las poblaciones no gitanas a lo largo de la historia, es necesario advertir que los valores y formas de vida de la sociedad no son un referente para los gitanos, quienes prefieren atribuirse la responsabilidad de su fracaso -económico, salud, pobreza, etc.- que reconocer que éste puede ser una consecuencia de ser despreciados por la sociedad, prefiriendo disfrutar de un universo de valores, principios y cultura propios (Mamontoff, 2009 y 2010). Siguiendo esta idea, Ruggiero y Taylor (1997) confirmaron que las personas estigmatizadas prefieren responsabilizarse del fracaso que aceptar que son rechazadas por grupos más poderosos, aunque suelen profesar una autoestima superior a la de grupos no estigmatizados (Smith y Tyler, 1997). Pero las comunidades gitanas, a pesar de su marginalidad y estigmatización por las sociedades no gitanas, han desarrollado un importante patrimonio cultural intangible (PCI) a lo largo de su existencia como comunidad y según el contexto que les ha tocado vivir. Por ello, el objetivo de este trabajo es identificar, mediante una labor exploratoria, los distintos ámbitos del patrimonio cultural inmaterial de las comunidades gitanas del sur de Francia, según las características que la Organización de las Naciones Unidas para la Educación, la Ciencia y la Cultura (UNESCO) acordó en 2003 en la Convención para la Salvaguardia del Patrimonio Cultural Inmaterial, con el fin de detectar sus posibilidades de valorización turística. Cabe apuntar que esta valorización está amenazada por la homogeneización cultural producto de la globalización y por los mecanismos de discriminación no consciente que existe tanto en la sociedad como en los poderes públicos. El artículo se ha dividido en un apartado conceptual, donde se explica el concepto de patrimonio cultural inmaterial; uno metodológico, donde se detallan los criterios metodológicos seguidos; uno de análisis del PCI gitano y del punto de vista de las administraciones públicas; otro con las conclusiones más relevantes de este estudio $y$, finalmente, la bibliografía utilizada.

\section{Patrimonio cultural inmaterial}

Origet du Cluzeau (2004) define el patrimonio cultural inmaterial (PCI) como las prácticas, representaciones, expresiones, conocimientos y saber-hacer que las comunidades, los grupos y los individuos reconocen como parte de 
su patrimonio cultural, el cual se transmite de generación en generación y es recreado por las comunidades y los grupos en función del medio donde viven, de su interacción con la naturaleza y de su historia, procurándoles un sentimiento de identidad y de continuidad que promueve el respeto por la diversidad cultural y la creatividad humana.

Conviene recordar que la toma de conciencia hacia el PCl se remonta a 1973, en Bolivia, a partir de discusiones sobre el reconocimiento de los derechos de autor en las artes tradicionales populares. Sin embargo, no es sino hasta 2003 cuando los Estados miembros de la UNESCO llegan a un acuerdo para la salvaguarda del PCI (Giguère, 2006). Es importante señalar que este acuerdo se inspira en una ley japonesa de 1950 sobre la protección de las propiedades culturales, que pretendía proteger a los poseedores de conocimientos culturales excepcionales, reanimar la identidad para la diversificación de la cultura y favorecer la transmisión de estos conocimientos frente a la modernización (Isomura, 2004). Desde 1992, cuando los Estados miembros de la UNESCO utilizaron por primera vez la expresión patrimonio cultural inmaterial para designar a la producción espiritual de los pueblos, hasta 2003 cuando la UNESCO aprobó la Convención para la Salvaguardia del Patrimonio Cultural Inmaterial, en la que se reconoce la necesidad de apoyar manifestaciones y expresiones culturales carentes de cualquier tipo de protección jurídica, el concepto de PCI fue ampliándose incorporando las tradiciones, las representaciones, las comunidades culturales, la memoria social. De manera paulatina, la UNESCO incrementó el interés por un patrimonio que representaba las identidades colectivas y la diversidad de las comunidades, añadiendo las tradiciones orales, usos sociales, actos festivos, conocimientos y prácticas con la naturaleza, saberes y técnicas artesanas (Unesco, 2010). Esta evolución ha sido importante porque reconoce las especifidades culturales $y$ ha permitido la salvaguarda de las identidades regionales que se encuentran en peligro de extinción por los efectos de la globalización, además de que sitúa al $\mathrm{PCl}$ en las mismas condiciones de protección que el patrimonio cultural o el natural (Origet du Cluzeau, 2004). En este contexto, la historia social de la cultura de las minorías gitanas ha demostrado que son portadoras de un rico patrimonio inmaterial en los diferentes ámbitos amparados por la UNESCO.

Según la Convención, las tradiciones, las expresiones orales y las lenguas comprenden una gran variedad de formas: cuentos, leyendas, proverbios, enigmas, cantos, mitos, poemas épicos, rezos, representaciones teatrales, etc. Las artes del espectáculo están constituidas por la música, la danza y el teatro tradicional. Las 
prácticas sociales, los rituales y los acontecimientos festivos estructuran la vida de los grupos sociales y forman parte de su identidad y memoria colectiva. Podemos encontrarlas en rituales relacionados con nacimientos, bodas, funerales, que a su vez pueden tener un carácter público o privado. El artesanado tradicional tiene que ver con los múltiples conocimientos y saberes de los grupos que se expresan en el trabajo artesanal con una gran diversidad de materiales y que hacen referencia a sus propias identidades sociales.

\section{Metodología}

Esta investigación se circunscribe en una metodología cualitativa y es una aproximación exploratoria al patrimonio cultural inmaterial de los gitanos, quien un segundo momento se aplicaría en las comunidades gitanas que habitan en distintos emplazamientos del sur de Francia y de Cataluña, en España. Para esta primera etapa se trabajó mediante la combinación de técnicas. Por una parte, técnicas de observación y revisión documental, con una exploración sociohistórica de la cultura gitana encaminada a verificar que sus manifestaciones culturales inmateriales corresponden a los criterios de clasificación de la UNESCO, para lo cual se ha examinado tanto la bibliografía de los autores especializados en este colectivo como algunas propuestas públicas relacionadas con esta minoría. Por la otra, una encuesta de 10 ítems -cinco orientados a identificar motivos para la integración en la sociedad no gitana y cinco para la no integración- dirigida a recopilar información sobre las posibilidades de integración de estas comunidades, efectuada a 100 individuos no gitanos ( 55 hombres y 45 mujeres, de entre 22 y 60 años). La muestra se eligió, a conveniencia de la investigadora, entre la población de empleados del sector social, conocedores de la situación de la comunidad gitana de la ciudad de Perpiñan (Francia). Por tratarse de un estudio exploratorio, en ningún caso se pretende obtener conclusiones extrapolables al conjunto de la población gitana, puesto que cada contexto cultural, geográfico y político determina el patrimonio cultural inmaterial y a la población no gitana.

\section{Resultados}

\section{El patrimonio inmaterial gitano}

Con referencia a los distintos ámbitos que forman parte del PCI, reconocidos por la UNESCO, hemos encontrado varios de ellos entre las comunidades gitanas 
en general. El primero al que vamos a referirnos es el de las tradiciones y expresiones orales. En este sentido, es necesario prestar atención a los idiomas con los que se expresan estas comunidades. Hemos de tener en cuenta que la cultura gitana está marcada por la tradición oral y que también es producto del 161 contacto con otros entornos sociolingüísticos como resultado de la movilidad que históricamente ha tenido. La lengua gitana, o romani sib, ha evolucionado hacia diferentes dialectos, desde sus orígenes indoeuropeos. Reyniers (I998) enumera como dialectos del original romaní, entre otros, al balcánico, cárpato, ruso-polaco, finlandés, ucraniano, vlax, anglorromaní, íberorromaní o caló, sin que, según este autor, se puedan situar estrictamente repartidos en un mapa geográfico. Esta gran diversidad de dialectos no ha impedido que los colectivos gitanos estén en un acelerado proceso de pérdida del uso de la lengua romaní (Lörincz, 2003; Reyniers, 1998). Pero la identidad gitana se define a partir de pertenecer a una comunidad, a un modo de vida, a un lugar geográfico y por hablar una lengua propia. A menudo los gitanos son bilingües o multilingües. Por ejemplo, los gitanos del departamento francés de los Pirineos Orientales tienen sus orígenes en España y hablan catalán, español y francés, además de su dialecto específico, el caló. El uso de este dialecto es estrictamente entre gitanos, o con personas muy próximas a la comunidad gitana,y los diferencia claramente de los que no pertenecen a ella, denominados "payos", lo cual les da un fuerte componente de identidad (Escudero, 2003).

Por otro lado, encontramos numerosos proverbios y aforismos, cuentos $y$ leyendas gitanos, con numerosos mitos, leyendas que hacen referencia al arte de vivir y a la espiritualidad, que son clave en el universo gitano (Geneuil, 2007). Sin embargo, uno de los elementos de identidad más relevante de los gitanos es el flamenco o cante jondo. Hay muchas teorías alrededor del origen del cante flamenco. Reyniers (1998) sostiene que apareció a principios del siglo XIX en Andalucía, España, como una forma creativa dentro de la tradición de los cantos del dolor, entonados por los proscritos de las culturas hispánicas y orientales. Thede (1999) dice que surgió hacia finales del siglo XVIII en Andalucía con unos orígenes que suscitan todavía muchos debates entre los especialistas. Leblon (1990) afirma que los gitanos consiguieron hacer evolucionar música original andaluza hacia el flamenco. Cualquiera que sea su procedencia, el flamenco hoy forma parte de la cultura andaluza del sur de España.

La interpretación del flamenco requiere una guitarra, a veces una bandurria, el cante y la danza o baile flamenco, dando pie a representaciones artísticas y 
teatrales. Thede (1999) apunta que el flamenco es un arte noble que obtiene un realce notable con el acompañamiento de la guitarra y la danza. A estas tres formas inseparables de expresión artística hay que añadir las palmas rítmicas y las castañuelas, pequeño instrumento musical de madera que se coloca alrededor del dedo pulgar de cada mano y se hacen claquear al ritmo de la música. Hombres y mujeres danzan al ritmo de la música, acompañados de las palmas, las castañuelas y los taconeos de los zapatos del grupo de acompañamiento. Esta música se instala en la tradición de las comunidades gitanas hasta el punto de que, a partir de finales del siglo XIX, el flamenco se desarrolla como espectáculo, siendo las comunidades gitanas del sur de España (Andalucía) las que se identifican más rápidamente con él (Guiguères, 2009). Un buen ejemplo lo constituye El Sacromonte de Granada (Andalucía, España), una montaña rocosa, repleta de grutas naturales, situada en plena ciudad de Granada, y que se convirtió en un lugar típicamente gitano habilitado para el espectáculo: cuevas donde las comunidades gitanas han conciliado la tradición con la rentabilidad en un espacio perfectamente organizado, con un bar, para el consumo de bebidas alcohólicas, y un "tablao flamenco", escenario donde las mujeres y los hombres gitanos bailan, cantan y tocan la guitarra para un público mayoritario de turistas.

El nomadismo y las corrientes migratorias de las comunidades gitanas han provocado la diversificación de su música. Además del flamenco, se ha relacionado a los gitanos con otros estilos musicales, como la música húngara, los cantos folclóricos rusos, la rumba y el jazz, incorporando otros instrumentos procedentes de la tradición musical occidental, como la flauta y el violín, para desarrollar géneros musicales producto de la fusión con el jazz, el rock, el blues, la salsa, etc. (Thede, 1999). No obstante, algunos grupos han perdido toda su tradición musical, mientras que otros han conseguido conservarla sin utilizarla comercialmente.

En el terreno del espectáculo, se ha asociado a los gitanos con el circo.Algunos se han especializado en el adiestramiento y exhibición de animales, como osos, monos y cabras. Reyniers (1998) indica que se conocen exhibidores de osos desde el siglo XII en Turquía y más tarde en los Balcanes, y que el teatro ambulante y el teatro de marionetas son formas de expresión gitanas con grupos conocidos de actores ambulantes en Europa a partir de los años cincuenta del siglo XX, interpretando autores clásicos en lengua romaní. 
Los rituales y los acontecimientos festivos están muy presentes también en la tradición cultural gitana, fundamentalmente las bodas, los nacimientos y los funerales, aunque son manifestaciones que, a menudo, sólo se desarrollan en el ámbito privado y son de muy difícil acceso para los que no son gitanos.

Las comunidades gitanas son reconocidas por su gran talento musical, pero no lo son, o son menos conocidas, por su habilidad en la artesanía. Históricamente, la artesanía fue muy común y estuvo muy diversificada entre la población gitana, aunque los efectos de la globalización han contribuido a que muchas de estas prácticas hayan desaparecido. Escultores, orfebres y artesanos de la madera han destacado entre las poblaciones gitanas de Europa del Este (Reyniers, 1998; Liégeois, 1983 y 2009). En este sentido, y a pesar de que se ha relacionado el trabajo que los gitanos han hecho con la madera con el adorno de utensilios domésticos, rústicos y funcionales, algunos artistas húngaros, por ejemplo Jakab Orsós y Vince Horváth, han perfeccionado estas técnicas (Reyniers, 1998). Otra expresión artística practicada por los gitanos y poco conocida es la pintura. Utilizan tela, vidrio o piedras como soporte para pintar. Los motivos de las pinturas otorgan un rol importante a la mujer, a la vida cotidiana, al sufrimiento y a la libertad. De todas maneras, y no obstante estas numerosas manifestaciones artísticas, los gitanos son considerados todavía como un pueblo estigmatizado.

A pesar de esta diversidad y riqueza en el PCl gitano, la UNESCO no ha reconocido todavía como patrimonio de la humanidad ninguna forma cultural gitana. Asimismo, hasta el periodo 2008-2009, se observa un déficit de candidaturas vinculadas con la cultura gitana, lo cual puede explicarse por los ya expresados índices de marginalidad hacia estas comunidades. Tal déficit es una verdadera barrera para la explotación turística de estos atractivos que, convertidos en productos turísticos, mejorarían, sin lugar a dudas, los niveles socioeconómicos y culturales de las comunidades, contribuyendo al abandono de la marginalidad.

Integración y no integración de las comunidades gitanas

A continuación se analizan los datos procedentes de la encuesta, los cuales son sólo indicativos por tratarse de un estudio exploratorio.

El cuadro I permite observar el nivel de acuerdo o desacuerdo entre los motivos que pueden frenar la integración de las comunidades gitanas en las sociedades no gitanas. Podemos ver que hay un fuerte consenso mayoritario 
Poblaciones sin fronteras $y$

valorización del patrimonio cultural

intangible: el caso de los gitanos

entre todos los encuestados en los ítems relacionados con las razones de la no integración de los gitanos en la sociedad occidental, donde destaca con un $100 \%$ la respuesta de que los gitanos no se integran porque viven en comunidades propias.

El cuadro 2 se refiere a los motivos que permitirían que los gitanos se integraran en la sociedad y abandonaran la marginalidad.

Cuadro I. Motivos de la no integración de los Gitanos

\begin{tabular}{|c|c|c|c|c|}
\hline & & $\begin{array}{c}\text { Estoy de } \\
\text { acuerdo } \\
(\%)\end{array}$ & $\begin{array}{c}\text { No estoy } \\
\text { de acuerdo } \\
(\%)\end{array}$ & $\begin{array}{c}\text { NS/NC } \\
(\%)\end{array}$ \\
\hline 1 & $\begin{array}{l}\text { Los Gitanos no se integran porque viven en co- } \\
\text { munidades propias }\end{array}$ & 100 & 0 & 0 \\
\hline 2 & $\begin{array}{l}\text { Los Gitanos no se integran porque no tienen } \\
\text { recursos económicos }\end{array}$ & 93 & 4 & 3 \\
\hline 3 & $\begin{array}{l}\text { Los Gitanos no se integran porque tienen niveles } \\
\text { muy bajos de educación y formación }\end{array}$ & 92 & 3 & 5 \\
\hline 4 & $\begin{array}{l}\text { Los Gitanos no se integran porque viven al mar- } \\
\text { gen de los normas de la sociedad occidental }\end{array}$ & 92 & 5 & 3 \\
\hline 5 & Los Gitanos no se integran porque son nómadas & 86 & 10 & 4 \\
\hline
\end{tabular}

Fuente: Elaboración propia

Cuadro 2. Motivos QUe PODRÍAN PERMITIR LA INTEGRACIÓN DE LOS GITANOS

\begin{tabular}{|c|c|c|c|c|}
\hline & & $\begin{array}{c}\text { Estoy de } \\
\text { acuerdo } \\
\text { (\%) }\end{array}$ & $\begin{array}{c}\text { No estoy } \\
\text { de acuerdo } \\
(\%)\end{array}$ & $\begin{array}{c}\text { NS/NC } \\
(\%)\end{array}$ \\
\hline 6 & $\begin{array}{l}\text { Los Gitanos pueden integrarse porque tienen } \\
\text { capacidades artísticas }\end{array}$ & 95 & 2 & 3 \\
\hline 7 & $\begin{array}{l}\text { Los Gitanos pueden integrarse porque tienen } \\
\text { habilidades manuales }\end{array}$ & 90 & 0 & 10 \\
\hline 8 & $\begin{array}{l}\text { Los Gitanos pueden integrarse porque son } \\
\text { creativos }\end{array}$ & 89 & 5 & 6 \\
\hline 9 & $\begin{array}{l}\text { Los Gitanos pueden integrarse porque tienen una } \\
\text { cultura rica }\end{array}$ & 73 & II & 16 \\
\hline 10 & $\begin{array}{l}\text { Los Gitanos pueden integrarse porque están } \\
\text { dotados intelectualmente }\end{array}$ & 6 & 62 & 32 \\
\hline
\end{tabular}

Fuente: Elaboración propia 
Respecto a los resultados del cuadro 2, podemos comprobar cómo los encuestados reconocen que los gitanos pueden integrarse a la sociedad porque tienen habilidades artísticas ( $95 \%)$, habilidades manuales $(90 \%)$ y son creativos (89\%). En cambio, la estigmatización reaparece cuando $62 \%$ de los encuestados opina que la integración de los gitanos no será posible porque no están dotados intelectualmente.

Los poderes públicos y la minoría gitana

En la actualidad, las poblaciones que aún profesan comportamientos nómadas son consideradas por las instituciones europeas e internacionales como minorías vulnerables con una gran diversidad de problemas: analfabetismo, pobreza extrema, desempleo y dependencia de los programas sociales del Estado, además de que son identificadas como comunidades que tiene enormes dificultades para aceptar las normas educativas; que sufren marginación, discriminación y problemas de salud; $y$ que viven en guetos.

Una revisión de las políticas en Europa,y específicamente en la Unión Europea, indica que se está relanzando el debate sobre la igualdad de oportunidades hasta el punto de que está en el centro de las preocupaciones de los legisladores europeos. Mouchtouris (2008) afirma que a pesar de la voluntad de los poderes públicos por poner en práctica la mezcla social y acabar con la desigualdad y la dominación entre grupos, éstas continúan presentes entre nosotros.

Podemos constatar que, no obstante la existencia de voluntades explícitas de los poderes públicos en la lucha por la inserción de estas comunidades y del reconocimiento de su cultura, esta categorización o discriminación positiva mantiene la separación entre gitanos y no gitanos y perpetúa los estereotipos y estigmas sobre el grupo discriminado. De manera consciente, existe la voluntad de luchar por la igualdad de oportunidades, pero la continuada inclusión de las comunidades gitanas en categorías de marginación y estereotipadas activa, de modo no consciente, las opiniones y prácticas discriminatorias. Así, no es de extrañar que la UNESCO rechazara la candidatura para que el flamenco fuera reconocido como patrimonio cultural inmaterial en 2006, a pesar del precedente de 1994, cuando el propio organismo en su Consejo Ejecutivo ( $144^{a}$ sesión, abril de 1994), se propuso el desarrollo de proyectos culturales para los gitanos del sur de Europa, sosteniendo que un inventario de sus expresiones culturales, representaciones artísticas y sociales, contribuiría a la 
comprensión de las aportaciones de los gitanos a la cultura y haría desaparecer los estereotipos sobre sus formas de vida.

\section{Conclusiones e implicaciones}

Respecto al presente análisis sobre el patrimonio intangible gitano, en especial las opiniones de los no gitanos en relación con su integración y las actuaciones de los poderes públicos europeos en torno a las minorías, no se persigue universalizar sus resultados al conjunto de la población gitana ni se pretende extrapolar las opiniones de los no gitanos, ya que tratándose de un estudio exploratorio sólo busca introducirse al fenómeno para seguir desarrollando otras etapas del mismo estudio.

En cuanto al PCl gitano, hemos señalado que contiene la mayoría de las formas definidas por la UNESCO y que significan una riqueza cultural muy importante. Algunas manifestaciones como el flamenco, proverbios y aforismos, cuentos y leyendas gitanos, mitos, tradiciones teatrales que hacen referencia al arte de vivir y a la espiritualidad de los gitanos, son parte de un patrimonio en peligro de perderse de manera irreparable, pudiendo constituirse en algunas de sus formas como atractivos turísticos.

Con relación a los poderes públicos, y como hemos detallado en la parte analítica, la UNESCO no ha reconocido todavía ninguna forma del PCI gitano. Un pronunciamiento de estas características permitiría poner a salvo su identidad y valorizar su cultura, lo cual sería fundamental para introducir nuevas lecturas de las comunidades gitanas por los no gitanos. Pero actualmente, y como ha mostrado el resultado de la encuesta, está instalada en la memoria colectiva de la sociedad "paya" la percepción de los gitanos como marginales y nómadas y con toda clase de estereotipos y prejuicios. En este sentido, los no gitanos dan a conocer de inmediato los tópicos y estigmas sociales con los gitanos cuando opinan que el hecho de que vivan en comunidad, tengan dificultades económicas y niveles muy bajos de formación y educación, cuenten con sus propias formas de organización con normas ajenas a las sociedades no gitanas, así como su nomadismo y bajo nivel intelectual, dificultan la integración. Sin embargo, reconocen que pueden integrarse si desarrollan sus habilidades, su creatividad $y$, en definitiva, su cultura. También las instituciones públicas los clasifican en categorías que favorecen su estigmatización o, bien, con el impulso de políticas positivas, tienden a darles tratamientos específicos que a los ojos del 
conjunto de la población los margina. Europa trata de promover la igualdad de oportunidades y la UNESCO anunció la voluntad de reconocer el patrimonio relacionado con las identidades minoritarias, pero hasta ahora los gitanos no han tenido acceso al reconocimiento de su PCl, el cual significaría una contribución trascendental para las comunidades gitanas y una oportunidad de explotación turística.

Desde una perspectiva de turismo, nos parece que la valorización del patrimonio intangible de los gitanos podría ser un vector de integración económico y social así como un medio para rehabilitar a las comunidades que han perdido la posibilidad de ejercer sus tradiciones. Preservar y valorizar el patrimonio intangible es hoy en día una prioridad de la industria turística. Si nos referimos al sur de Francia, es necesario investigar cuál es la mejor forma de proceder puesto que esta región es fronteriza con Cataluña y ambas regiones tienen poblaciones gitanas. Una política de desarrollo turístico se debería realizar con un diálogo entre actores del turismo de los dos lados de la frontera (francesa y española) para responder a preguntas como qué medios y procedimientos son necesarios para valorizar el patrimonio intangible de los gitanos, cómo desarrollar el interés turístico hacia esas poblaciones sin desnaturalizarlas y haciéndolas participar de los beneficios económicos del negocio. El resultado de este trabajo constata que los gitanos tienen un potencial artístico importante que han podido explotar, con mejor o peor suerte, y según los contextos históricos y geográficos en los que han vivido. Si además se le da valor desde una visión transfronteriza, las posibilidades de convertirse en atractivo turístico mayores ya que se pueden ofrecer al turista recorridos más largos y ricos. Desde este punto de vista, el turismo no es sólo un motor económico sino una herramienta de valorización y de integración humana, que debe permitir a los grupos minoritarios y socialmente excluidos preservar y reencontrar una identidad que les ayude a obtener recursos económicos. El desarrollo de una política turística transfronteriza puede contribuir a situar a estas comunidades en el nuevo espacio europeo sin fronteras, que incita libremente a la movilidad de los ciudadanos.

\section{Sugerencias para futuras investigaciones}

Como hemos explicado, el trabajo que presentamos constituye una primera etapa de una investigación más profunda sobre el patrimonio cultural inmaterial 
de las comunidades gitanas. En una segunda parte se analizarán los diferentes ámbitos del PCl en comunidades específicas de Perpiñan (Francia) y Barcelona (España), y se realizará un estudio sobre la percepción 0 -con una muestra estadísticamente representativa- de la población no gitana respecto a las posibilidades de integración de los gitanos a la sociedad "paya", para contrastar las hipótesis vinculadas con posibles correlaciones entre rechazo social y políticas públicas.

\section{FUENTES CONSULTADAS}

Escudero, J.P. (2003). “Une société plurilingue”, en B. Leblon, J.P. Salles y J.P. Escudero (dirs.). Le Livre des Gitans de Perpignan. París: L'Harmattan, 47-66.

Geneuil, G.P. (2007). La Symbolique gitane. París: Oxus.

Giguère, H. (2006). "Vues anthropologiques sur le patrimoine culturel immatériel, un ancrage en basse Andalousie". Anthropologie et Sociétés, 30 (2), I07- 127.

Isomura, H. (2004). “Le Japon et le patrimoine immatériel”. I'Internationale de l'imaginaire. Le patrimoine culturel immatériel. Les enjeux, les problématiques, les pratiques. Nouvelle série, I7, 68-79.

Leblon, B. (1990). Musiques tsiganes et Flamenco. París: L'Harmattan. Liégeois, J.P. (1983). Tsiganes. París: La Découverte/Maspero.

(2009). Roms et Tsiganes. París: La Découverte.

Lörincz, I. (2003). "Aspects linguistiques et socioculturels de l'échec scolaire des enfants tsiganes en Hongrie”. La Linguistique, 39, I33-148.

Mamontoff, A.M. (2009). “Travail et identité chez les Tsiganes”. Les cahiers du CRES, I39-I52.

(20I0).“Discrimination non consciente des sociétés contemporaines", en A. Mouchtouris (dir.). Perpiñán: Presses Universitaires de Perpignan.

Mouchtouris, A. (dir.) (2008). Mixité sociale et Egalité des chances. Perpiñán: Presses Universitaires de Perpignan. (Inédito).

Origet du Cluzeau, C. (2004). "Tourisme prédateur, tourisme salvateur”. La Revue Espaces, 215, Tourisme et Loisirs, 22-28.

Reyniers,A. (1998). Tsigane heureux si tu es libre. París: Éditions UNESCO. 
Ruggiero, K. y D. Taylor (1997). "Why Minority Group Members Perceive or Do Not Perceive the Discrimination that Confronts them:The Role of Self-esteem and Perceive Control". Journal of Personality and Social Psychology, 72, 373-389.

Smith, H.J. y T.Tyler (1997). "Choosing the Right Pond:The Impact of Group Membership on Self-esteem and Group-Oriented Behavior". Journal of Experimental Social Psychology, 33, I46-I 70.

Thede, N. (1999). Gitans et Flamenco. Les rythmes de l'identité. París: L'Harmattan. UNESCO. (2010) Convencion para la salvaguardia del patrimonio cultural inmaterial. Disponible en : http://portal.unesco.org/es/ev.phpURL_ ID=|77| 6\&URL_DO=DO_TOPIC\&URL_SECTION=20I.html 